\title{
Interactive comment on "Revisiting properties and concentrations of ice nucleating particles in the sea surface microlayer and bulk seawater in the Canadian Arctic during summer" by Victoria E. Irish et al.
}

\section{Anonymous Referee \#1}

Received and published: 1 October 2018

The manuscript titled "Revisiting properties and concentrations of ice nucleating particles in the sea surface microlayer and bulk seawater in the Canadian Arctic during summer" by Irish et al. presents an ice nucleation study using droplets generated from bulk and surface Arctic seawater. The authors use filtration to estimate the size of the ice nucleating agent. After heating the water, freezing temperatures of droplets decreased. Finally, the authors also measure salinity, numbers of bacteria and phytoplankton cells and correlate them to the temperature at which $10 \%$ of the droplets froze, $T_{10}$, in each sample. Chlorophyll satellite data was also correlated with $T_{10}$. Warmer freezing tem- 
peratures correlated with decreasing salinity and decreasing bacteria concentrations. The authors also found warmer freezing temperatures in this study compared with the one conducted in 2014.

Overall, I find the manuscript unsuitable for ACP in the present form as I fail to see new findings in chemistry and physics. Furthermore, the results and data analysis are essentially identical to Irish et al. (2017) with the only difference of the sampling depth due to use of a rotating drum. Granted, the data here is new because it is taken at a later year and with a well defined scientific approach. However, the results and analysis in this manuscript are essentially copies of the author's previous paper without any scientific extension. In my major comments below, I have introduced some ideas to extend their work. As it is now, I do not find any conclusions anywhere in the manuscript and the word is not even written except for the title of the section. Please understand the difference between conclusions and observational results. Overall, I will not recommend publication in ACP.

\section{Major Comments}

The authors lack ice nucleation physics. There is no nucleation theory or any application of active sites for comparison with other studies. This is because there is no surface area estimate of insoluble material in their droplets. If water and filters are still available, then total particulate mass or surface area of insoluble particles could be obtained. Forexample, filters can be washed, dried and weighed and water can be used to get a size distribution from the flow cytometry. Another point is that correction for freezing point depression follows a water activity approach that Koop and Zobrist (2009) used for other biogenic ice nucleators. A plot of INP vs. $\Delta a_{\mathrm{w} \text {, het }}$ could be made which allows the authors to discusses the effect (or lack thereof) of ionic activity on ice nucleation. $\Delta a_{\mathrm{w} \text {, het }}$ could be compared with other biogenic ice nucleators.

The authors lack cloud and atmospheric physics. The authors could use SSA production formulations measured from previous studies to calculate the number of ice

Printer-friendly version

Discussion paper
Interactive

comment 
forming particles per liter of air. Vertical and horizontal motion (updraft and $10 \mathrm{~m}$ high wind speed) provided from meteorological data, or reanalysis can then be used to give some notion of the total ice nucleating particles in air. Does the $T_{10}$ data or some other percentage of droplets frozen, correspond to a mixed phase cloud base or ice water path from satellite data?

The authors lack ocean physics. There is countless studies documenting the enrichment or lack of enrichment of material in a microlayer with respect to bulk water. These materials can be surfactants, insoluble particles, or other materials such as proteins and polysaccharides. The interesting result from both the present manuscript and Irish et al. (2017) is that the ice nucleation ability is the same for bulk and microlayer water. This could mean that the ice nucleating particles are not surface active? What compounds in the ocean are uniformly distributed through the microlayer and bulk water? Are there soluble surfactants in bulk water that are transported to the microlayer? Is there a difference in surface tension between microlayer and bulk water?

p.6 I.26 - p.7 I.1-5: Clearly, freezing temperatures warmer than pure water indicate heterogeneous droplet freezing. However, the "procedural blank" resulted in freezing temperatures at $-16^{\circ} \mathrm{C}$. How is it possible that freezing was observed below this temperature? On I.4-5 the answer is given that rinsing times were different (a fact not mentioned in the experimental section), so the freezing temperatures of the "blank were due to (cross-)contamination. How can we then compare any measurements of these to the blanks? In microlayer samples, Fig. S2a shows that no data below $-16^{\circ}$ $\mathrm{C}$ can be trusted. If these were the blanks for the experiments, the freezing curves should follow exactly the procedural blank data which would be seen as a discontinuity (step in the graph) of the freezing temperature around $-16^{\circ} \mathrm{C}$. This is not the case and so I would conclude that this blank has nothing to do with the data at all and suggest there is no blank experiment for these data using the same procedures. How is this data at all trustable? I now understand why the authors use $T_{10}$ and not median freezing as reported in Koop and Zobrist (2009), because if they did there would be

Printer-friendly version

Discussion paper
Interactive

comment 
no difference with their freezing points of microlayer water and the blanks. I am very concerned that freezing temperatures were due to cross contamination because of the lack of reproducibility for the blanks, as the freezing temperatures of the microlayer and bulk seawater do not follow the blanks at all.

p.6 I.26 - p.7 I.1-5: In the same section I find that freezing temperatures of filtered water (through the sampler) are less than ultra pure water (not through the sampler) by about $5-10^{\circ} \mathrm{C}$. I doubt the seawater was more pure than the ultrapure water, so what is wrong here? Are the authors certain of the freezing point correction with the E-AIM model? Is there an uncertainty of $\pm 5-10^{\circ} \mathrm{C}$ ? I cannot accept this result and it makes me seriously doubt the accuracy of these experiments. The blank should be the lowest freezing temperature.

Figure S3: The ultrapure water data here is about $5^{\circ} \mathrm{C}$ different from the ultrapure water in Fig. S2. This indicates to me that the authors experiment is reproducible to $\pm 5^{\circ} \mathrm{C}$. This is a large uncertainty which is not stated in the paper.

p.3 I.12: It is not possible to name your instrument as an autosampler when for the majority of the stations the authors had to manually rotate the drum.

Equation 1: How does this equation account for the possibility of multiple INP's? Does the author observe more than one nucleation event in a droplet before it crystalizes? How can they tell if the droplet has 1 or 100 INPs inside? This method of analysis is 45 years old, do the authors have an updated analysis for quantifying freezing?

p.8 I.23-31: The logic is flawed here. Melting sea ice decreases salinity and releases bacteria to the ocean (p.24-26). Decreasing salinity yields warmer $T_{10}$ (Fig. 6 lower left). Decreasing salinity yields increasing bacteria (p.8 I.24-27). Finally, increasing bacteria yield lower $T_{10}$ (Fig. 6 upper left). So why do I read in p.8 I.30-31 that bacteria are fewer in melting sea ice and that bacteria increasing ice nucleation ability? This argument is highly contradictory.

Printer-friendly version

Discussion paper
Interactive

comment 
The most major problem I see in the manuscript is that it is a copy of the authors previous manuscript. The majority of section 4 is a repeat of Irish et al. (2017). The last paragraph of section 4 states that the only new finding is that concentrations are higher in 2016 than in 2014, but dismisses this finding due to a different sampler. This study ended in August 2016, but the Irish et al. (2017) paper (using only 2014 data) was submitted April 2017. Why wasn't the data presented in this manuscript used in Irish et al. (2017)? In any case, the authors should extend their work with new data and new discussion that includes physical and chemical understanding before I recommend publication in ACP.

\section{Minor Comments}

What are the "properties" of ice nucleating particles? How is that different from "freezing properties"? How is that different from "ice nucleation properties"? Properties of the microlayer? This word is used countless times but is never defined. Please include a sentence or 2 listing the actual property the author is talking about. I give one example on p.7 I.13-15. There I am told there is a positive correlation between freezing properties of microlayer and bulk water. How many properties correlate and what is actually being correlated? Please search for the word and replace it with something that is specific and measurable.

How can the droplet freezing technique analyse videos (p.4 I.11)? That must be automated or done by a person?

SYBR Green stains nucleic acids (p.5 I.25) which means it stains bacteria, phytoplankton, cyanobacteria, archaea and everything biogenic for that matter? The concentration derived from SYBR Green should be subtracted by the phytoplankton counts to get bacteria counts? In addition, there should be other things besided living organisms that stain, for example other biogenic particles such as cell fragments or gel-like particles. Are the authors counting this as well? Is there another name for these counts that should be used? 
There is no reason for a 2 sentence long subsection (section 2.5). Please incorporate this elsewhere.

p.6 I.22: It is not nice to the reader to be directed to the supplement for the first result. Please let me read about the main, exciting results first and then take me to those which are supplementary.

p.6 I.27: "In addition,....also..." is repetitive.

Interactive

comment

p.8 I.16-17: Why is it important to say that similar water masses were samples? The authors sampled from similar locations so why say more? Please tell me what exactly is similar about the water masses besides salinity.

p.10 I.12: The authors did not measure inter-annual variability. They did measure for a month in 2 different years.

\section{References}

V. E. Irish, P. Elizondo, J. Chen, C. Chou, J. Charette, M. Lizotte, L. A. Ladino, T. W. Wilson, M. Gosselin, B. J. Murray, E. Polishchuk, J. P. D. Abbatt, L. A. Miller and A. K. Bertram, Atmos. Chem. Phys., 2017, 17, 10583-10595.

T. Koop and B. Zobrist, Phys. Chem. Chem. Phys., 2009, 11, 10839-10850.

Interactive comment on Atmos. Chem. Phys. Discuss., https://doi.org/10.5194/acp-2018-641, 2018. 